\title{
Endoscopic mucosal resection with a multiband ligator for the treatment of Barrett's high-grade dysplasia and early gastric cancer
}

\author{
J. Espinel, E. Pinedo ${ }^{1}$ and G. Rascarachi \\ Departments of Gastroenterology, and 'Radiology. Hospital de León. Spain
}

\begin{abstract}
Aim: due to surgery's high mortality and morbidity, local therapeutic techniques are required for Barrett's high-grade dysplasia (BHGD) and early gastric cancer (EGC). Various techniques are available for endoscopic mucosal resection (EMR) in the GI tract. The "suck and cut" technique, which uses a transparent cap or modified multiband variceal ligator, is usually the most practiced method. A multiband ligator (ML) allows sequential resection without the need for submucosal injection and endoscope withdrawal. The objective of this study was to evaluate the efficacy and safety of EMR with a ML device in the treatment of Barrett's high-grade dysplasia and early gastric cancer.

Patients and methods: prospective study. Eight consecutive patients (4 men; median age, 62 years; range 38-89 years) with BHGD (4) or EGC (4) were treated. EMR was performed with a multiband ligator in order to create a pseudopolyp and then permit snare polypectomy of flat mucosal lesions. The pseudopolyp was resected by using pure coagulating current. No submucosal saline injection was administered before resection.

Results: a total of 8 consecutive patients were treated with the multiband ligator (ML) technique. Barrett's esophagus $(B E)$ : one patient with long $\mathrm{BE}$ received 3 EMR sessions. Three patients presented with short $\mathrm{BE}$ and received $1 \mathrm{EMR}$ session each. The histology of the EMR specimens confirmed a moderately differentiated adenocarcinoma with submucosal infiltration (1 patient) and BHGD (3 patients). Early gastric cancer (EGC): 3 patients had EGC (type IIa) and 1 patient had high-grade dysplasia. EMR was accomplished in 1 session for each patient. The histology of EMR specimens confirmed a mucinous adenocarcinoma with submucosal infiltration (1 patient), EGC (2 patients), and HGD (1 patient). Complications (mild esophageal stenosis, minor bleeding) occurred in 2 patients.
\end{abstract}

Conclusions: EMR has diagnostic and therapeutic implications, and represents a superior diagnostic modality as compared to traditional biopsy. By means of EMR the resected mucosa is

Received: 20-01-09.

Accepted: 06-03-09.

Correspondence: J. Espinel. C/ Brianda de Olivera, 13, esc-2, 3º -B. 24005 León, Spain.e-mail: espinel.jesus@gmail.com pathologically examined, and the lesion may be appropriately treated. EMR-ML is a safe and effective technique for the treatment of superficial lesions of the digestive tract, and is accepted as an alternative to surgical therapy for non-invasive lesions. Longterm follow-up is needed to determine the clinical impact of this method.

Key words: Barrett's esophagus. Eary gastric cancer. Dysplasia. Endoscopic mucosal resection. Multiband ligator.

Espinel J, Pinedo E, Rascarachi G. Endoscopic mucosal resection with a multiband ligator for the treatment of Barrett's high-grade dysplasia and early gastric cancer. Rev Esp Enferm Dig 2009; 101: 403-407.

\section{INTRODUCTION}

Barrett's esophagus represents a complication of longstanding gastroesophageal reflux, and therefore endoscopic surveillance is recommended. Esophagectomy has traditionally been recommended for patients who were found to have high-grade dysplasia during follow-up. Several endoscopic options have been evaluated for treating such patients. Endoscopic mucosal resection (EMR) is an endoscopic alternative approach in which the neoplastic epithelium is excised rather than ablated, allowing thus a definitive histological diagnosis and offering a potentially curative procedure. Available evidence suggests that EMR for Barrett's high-grade dysplasia (BHGD) has a success rate comparable to surgical treatment, but with fewer complications (1). Gastric cancer is one of the most common causes of cancer mortality worldwide. Early gastric cancer (EGC) is defined as adenocarcinoma that is limited to the gastric mucosa or submucosa regardless of whether regional lymph nodes are involved. Endo- 
scopic modalities for treating EGC, such as endoscopic mucosal resection, have been introduced over the last few decades. Although long-term outcomes for these techniques are not as well known as those following surgical resection, these modalities have the potential to cure EGC without the risks of surgery. EMR successfully eradicated EGC in 85 percent of cases (2). Five-year survival was 86 percent, a rate that is similar to the results reported for more aggressive surgical approaches (2).

EMR provides a new minimally-invasive alternative treatment for patients with Barrett's high-grade dysplasia (BHGD) and early gastric cancer (EGC), and guarantees a much better quality of life $(1,3)$. The present study reports our center's preliminary experience with the multiband ligator (ML) used for EMR in patients with BHGD and EGC.

\section{PATIENTS AND METHODS}

\section{Patients}

A prospective study including 8 patients (4 male; mean age: 62 years; range 38-89) between May 2006 and January 2009. Indications for EMR with a multiband ligator included Barrett's high-grade dysplasia (BHGD) and early gastric cancer (EGC). Four patients had BHGD and 4 had EGC.

Patients with high-grade dysplasia Barrett's esophagus: the biopsy's initial diagnosis was high-grade dysplasia. Three patients had a short BE. The length of the Barrett's segment in these patients was of 6,10 , and $13 \mathrm{~mm}$, respectively. One patient had a long $\mathrm{BE}$ whose length was of $40 \mathrm{~mm}$.

Patients with early gastric cancer: the biopsy's initial diagnosis was early gastric cancer (3 patients) and highgrade dysplasia (1 patient). The length of lesions ranged between 10 to $20 \mathrm{~mm}$.

\section{Methods}

A multiband ligator (ML) (Duette ${ }^{\circledR}$ Multiband Mucosectomy. Cook $^{\circledR}$ ) allows sequential resection with no need for submucosal injection or endoscope withdrawal. The mucosa is first suctioned into the ligating barrel (suction pressure: -320 mbar $\mathrm{x} 100$ ), and the rubber band is deployed in the same manner as in variceal ligation by creating a pseudopolyp. The polypoid bleb is then immediately resected with a minipolypectomy snare using pure coagulating current (Fig. 1). It does not matter whether the snare is placed above or below the band. Approximately, in $50 \%$ of cases the snare will automatically lie below the rubber band. After each resection, the specimen was extracted. In patients with Barrett's esophagus the procedure is initiated at the gastroesophageal junction and pursued circumferentially until the entire Barrett's

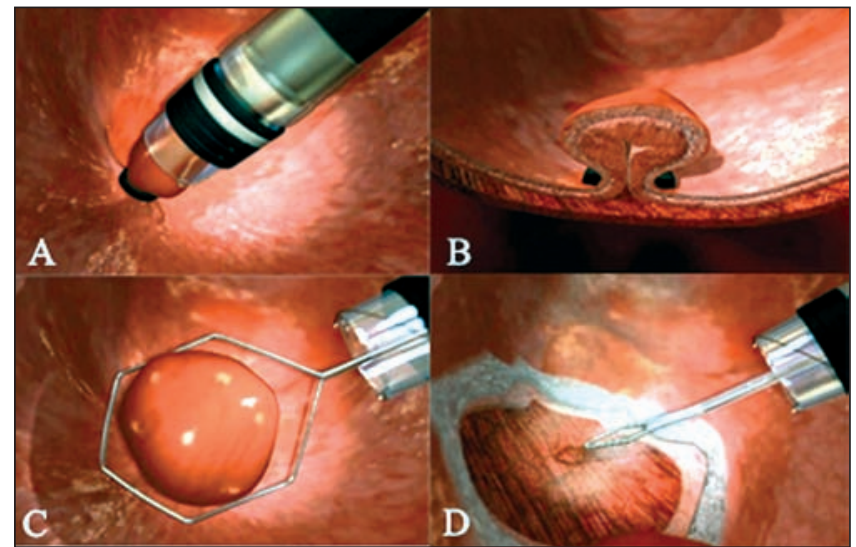

Fig. 1. EMR-ML technique (A to $D$ ): $M L$ uses the single rubber-band ligator to create a pseudopolyp and enable snare polypectomy (Picture: courtesy of $\left.\operatorname{Cook}^{\circledR}\right)$.

mucosa is completely removed in one or more sessions. EMR is performed in multiple sessions for long Barrett's segments. In patients with early gastric cancer, an argon plasma coagulator (APC) was initially applied in order to delimit the lesion. EMR was performed with the patient under unconscious sedation with titrated intravenous propofol. After EMR the patient is admitted to hospital for observation over 24 hours, and administered a proton pump inhibitor (PPI). Primary endoscopic follow-up is performed 4 weeks later on an outpatient basis. Repeated EMR sessions for cases of extensive Barrett's segment were carried out at 4-8-week intervals. If dysphagia occurred, patients were advised to go to hospital immediately. In case of stricture, dilation was performed. A written informed consent was obtained from all patients.

\section{RESULTS}

During a period of 32 months a total of 8 consecutive patients were treated with the multiband ligator (ML) technique.

\section{Patients with high-grade dysplasia Barrett's esophagus}

One patient had hiatal hernia and a circumferential Barrett's segment $4 \mathrm{~cm}$ in length. EMR-ML was accomplished during 3 sessions by using 12 bands (median, 4) (Fig. 2). Three patients presented with a short Barrett's segment (range: 6-13 mm). EMR-ML was accomplished in 1 session for each patient by using 1 band. The mean size of EMR-ML specimens measured before formalin fixation was $15 \mathrm{~mm}$. The histological exam of EMR-ML specimens found moderately differentiated adenocarcinoma with submucosal infiltration (1 patient) and BHGD (3 patients). Minor bleeding without clinical consequences occurred in 1 patient, and was controlled by local adrena- 


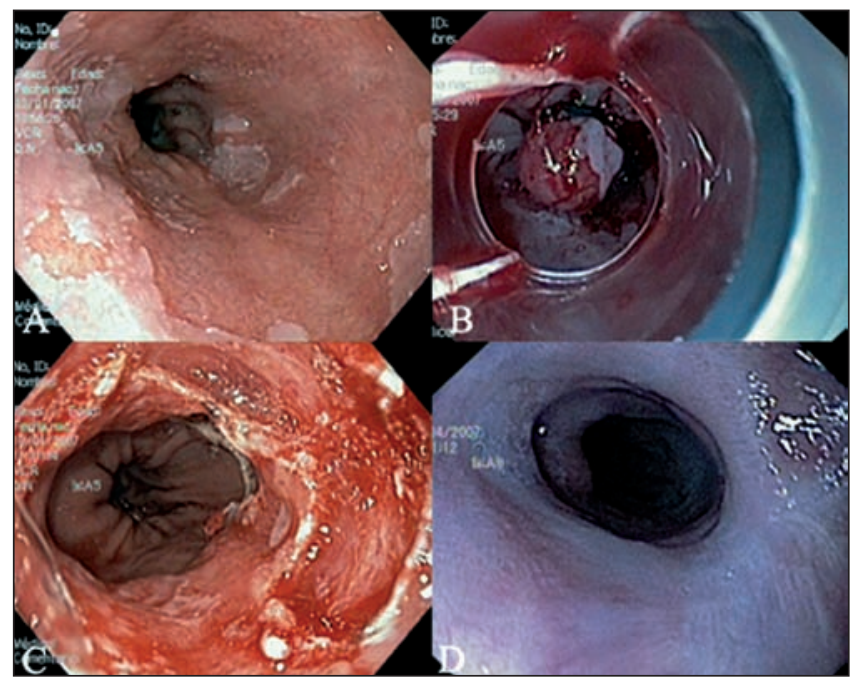

Fig. 2. A. 4-cm-long BE. B. ML was used to create a pseudopolyp. C. Barrett's mucosa is removed: the pseudopolyp was resected by minipolypectomy snare, using pure coagulating current. D. Complete restoration of the squamous epithelium.

line injection. A mild esophageal stenosis was encountered in 1 patient (long BE), and one session of endoscopic dilation was performed to relieve dysphagia. Surgery was indicated in a patient with adenocarcinoma. Nissen's procedure was indicated in a patient with hiatal hernia and a long Barrett's segment. Endoscopic surveillance was recommended for all patients. Regular follow-up did not detect any recurrent lesions. Patient characteristics and results are shown in table I.

\section{Patients with early gastric cancer}

Three patients had EGC (type IIa) and 1 patient had high-grade dysplasia. The length of lesions ranged between 10 and $20 \mathrm{~mm}$. EMR-ML was accomplished in 1 session in each patient by using a total 9 bands (median

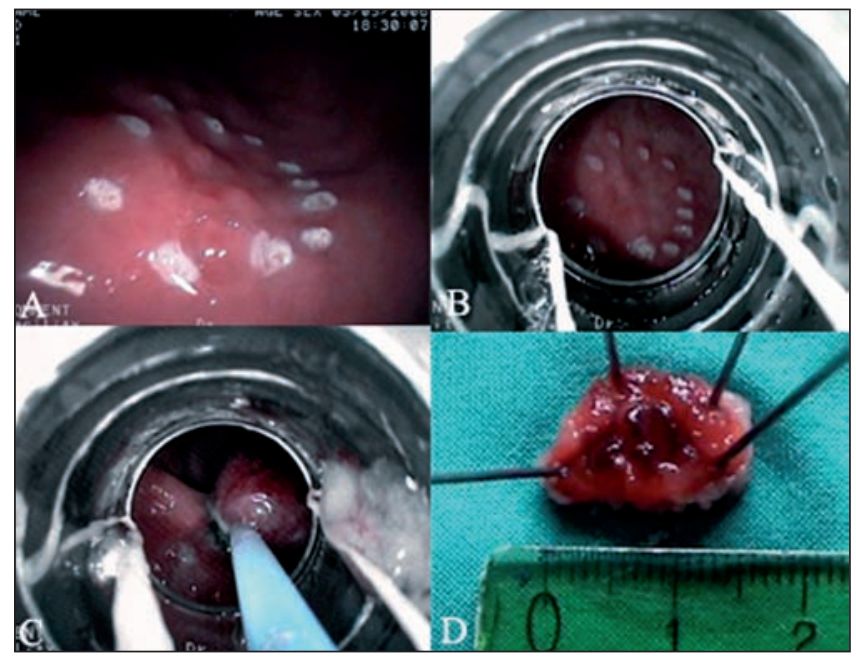

Fig. 3. EMR-ML technique in EGC patients (A to $D)$ : an argon plasma coagulator was initially applied to delimit the lesion.

2.2) (Fig. 3). The mean size of EMR-ML specimens measured before formalin fixation was $16 \mathrm{~mm}$. The histological exam of EMR-ML specimens confirmed mucinous adenocarcinoma with submucosal infiltration (1 patient), EGC (2 patients), and HGD (1 patient). Minor bleeding without clinical consequences occurred in 1 patient and was controlled by local adrenaline injection. Endoscopic surveillance was recommended for all our patients. Helicobacter pylori was eradicated. Regular follow-up did not detect any recurrent lesions. Patient characteristics and results are shown in table II.

\section{DISCUSSION}

EMR provides a new minimally invasive alternative treatment for patients with early gastric cancer (EGC) and Barrett's high-grade dysplasia (BHGD). Compared to surgery, EMR is associated with a distinctly lower

Table I. Patients with high-grade dysplasia Barrett's esophagus: characteristics and results

\begin{tabular}{|c|c|c|c|c|c|c|c|}
\hline Patients & $\begin{array}{c}\text { Short BE } \\
\text { (length/mm) }\end{array}$ & $\begin{array}{c}\text { Long BE } \\
\text { (length/mm) }\end{array}$ & $\begin{array}{l}\text { Initial diagnosis } \\
\text { (biopsy) }\end{array}$ & $\begin{array}{c}\text { EMR-ML } \\
\text { sessions }\left(n^{\circ}\right)\end{array}$ & Complications & $\begin{array}{c}\text { Final diagnosis } \\
\text { (EMR-ML) }\end{array}$ & Follow-up \\
\hline $\begin{array}{c}1 \\
M, 38 y\end{array}$ & & 40 & HGD & 4 & $\begin{array}{l}\text { Minor bleeding } \\
\text { Mild stenosis }\end{array}$ & HGD & $\begin{array}{c}\text { Nissen's procedure } \\
\text { ES }\end{array}$ \\
\hline $\begin{array}{c}2 \\
F, 42 y \\
\end{array}$ & 10 & & HGD & 1 & - & HGD & ES \\
\hline $\begin{array}{c}3 \\
M, 57 y\end{array}$ & 6 & & HGD & 1 & - & HGD & ES \\
\hline $\begin{array}{l}4 \\
F, 72 y\end{array}$ & 13 & & HGD & 1 & - & $A D C$ & Surgery \\
\hline
\end{tabular}

M: male; F: female; y: years; BE: Barrett's esophagus; HGD: high-grade dysplasia; ADC: adenocarcinoma; ES: endoscopic surveillance. 
Table II. Patients with early gastric cancer: characteristics and results

\begin{tabular}{|c|c|c|c|c|c|c|c|}
\hline Patients & $\begin{array}{l}\text { Length } \\
(\mathrm{mm})\end{array}$ & Location & $\begin{array}{l}\text { Initial diagnosis } \\
\text { (biopsy) }\end{array}$ & $\begin{array}{c}\text { EMR-ML } \\
\text { sessions }\left(n^{\circ}\right)\end{array}$ & Complications & $\begin{array}{l}\text { Final diagnosis } \\
\quad(E M R-M L)\end{array}$ & Follow-up \\
\hline 1 & & & & & & & \\
\hline$F, 65 y$ & 10 & Antrum & $\mathrm{EGC}$ & 1 & - & EGC & ES \\
\hline$\stackrel{2}{M}, 79 y$ & 20 & Antrum & EGC & 1 & Minor bleeding & EGC & ES \\
\hline $\begin{array}{c}3 \\
F, 89 y\end{array}$ & 15 & Incisura & EGC & 1 & - & $A D C$ & Surgery \\
\hline $\begin{array}{c}4 \\
M, 58 y\end{array}$ & 20 & Antrum & HGD & 1 & - & HGD & Es \\
\hline
\end{tabular}

M: male; F: female; y: years; EGC: early gastric cancer; HGD: high-grade dysplasia; ADC: adenocarcinoma; ES: endoscopic surveillance.

morbidity and guarantees a much better quality of life $(1,3)$. Mucosectomy is possible due to the existence of a loose adhesion between the submucosa and the muscular layer in the gastrointestinal tract's wall because of a different embryologic origin. This anatomic characteristic allows, for example, the injection of serum between the two layers, thus transforming a flat or depressed lesion into an elevated one. This permits the resection of the lesion, and reduces the risk of perforation. Various EMR techniques have been described $(4,7)$. The "suck and cut" technique, which uses a transparent cap (6) or multiband ligator (ML) (8), is the most commonly practiced method. Both techniques are similar concerning efficacy and safety for the endoscopic resection of early stage esophageal cancer (9). ML uses the single rubber-band ligator to create a pseudopolyp and allow a snare polypectomy of flat mucosal lesions. ML permits sequential resection without the need for submucosal injection or endoscope withdrawal (8).

Barrett's esophagus is considered a complication of long-standing gastroesophageal reflux. Recently, several endoscopic options have been evaluated for the treatment of patients with BHGD. Endoscopic mucosal resection (EMR) is an alternative endoscopic approach in which the neoplastic epithelium is excised rather than ablated, offering thus a definitive histological diagnosis and potentially curative treatment. Patients with a long Barrett's segment require piecemeal resection. We consider EMRML represents not only a reasonable treatment option but also the final step of the diagnostic work-up for patients with BHGD (10). Endoscopic resection of the most suspicious area in the Barrett's segment followed by histopathological evaluation of the specimen allows to assess infiltration depth and to estimate the risk for local lymph node metastasis (11). Available evidence suggests that EMR for BHGD has a success rate comparable to that of surgical treatment but with fewer complications. Serious complications with the EMR techniques are rare. The risk of complications increases with piecemeal resection $(1,12)$. Bleeding occurred in 9 to 46 percent of cases, and perforation has been rarely reported with an estimated incidence of $<1$ percent $(12,13)$. Esophageal stenosis is more common when the area of resection involves more than three quarters of the esophageal circumference or the length of the resection is longer than $30 \mathrm{~mm}$ (14). Stenosis arising after EMR may usually by resolved with endoscopic dilatation (14).

Gastric cancer still accounts for over 10 percent of annual cancer deaths, second only to lung cancer (15). One of the benefits of large-scale screening programs in high-risk areas has been the identification of early gastric cancer. Early gastric cancer is defined as adenocarcinoma limited to the gastric mucosa or submucosa regardless of whether regional lymph nodes are involved (T1Nx). The average size of early gastric cancers reported in the United States and Europe ranges from 1.7 to $3.0 \mathrm{~cm}$. EGC is detected in 10 to 20 percent of all resections for gastric carcinoma. Approximately 50 percent of tumors are limited to the mucosa, with the remainder also involving the submucosa. Depth of invasion generally parallels the macroscopic appearance of the tumor, as ulcerated lesions tend to have a deeper penetration versus flat lesions. Lymph node invasion is present in 10 to 20 percent of cases, and is more common ( 15 to 30 percent) in tumors that have invaded the submucosa. Distant metastases in EGC are infrequent (16). Survival rates of 85 to over 90 percent at five years after surgical resection have been reported in Japan and in the West (17). Endoscopic modalities for treating EGCs, such as EMR, have been introduced. These modalities have the potential to cure EGC without the risks of open or laparoscopic surgery. The primary characteristics of EGC that are most amenable to curative endoscopic resection by EMR are (18): elevated lesions less than $2 \mathrm{~cm}$ in size, depressed lesions less than $1 \mathrm{~cm}$ in size without ulceration and with absence of lymph node metastases on pretreatment staging studies. Long-term survival rates for EMR are comparable with those of radical surgery for patients diagnosed with early gastric cancers. Regional lymph-node metastasis in cancers limited to the mucosa is negligible. 
In summary, EMR has diagnostic and therapeutic implications. Represents a superior diagnostic modality compared to traditional biopsy. By means of EMR the resected mucosa is pathologically examined and the lesion may be appropriately treated. EMR-ML is a safe and effective technique for the treatment of superficial lesions in the digestive tract, and is accepted as an alternative to surgical therapy in non-invasive lesions. Long-term follow-up is needed in order to determine the clinical impact of this method.

\section{REFERENCES}

1. Ell C, May A, Gossner L, et al. Endoscopic mucosal resection of early cancer and high grade dysplasia in Barrett's esophagus. Gastroenterology 2000; 118: 670-7.

2. Takekoshi T, Baba Y, Ota H, Kato Y, Yanagisawa A, Takagi K, et al. Endoscopic resection of early gastric carcinoma: results of a retrospective analysis of 308 cases. Endoscopy 1994; 26: 352-8.

3. Nijhawan PK, Wang KK. Endoscopic mucosal resection for lesions with endoscopic features suggestive of malignancy and high-grade dysplasia within Barrett's esophagus. Gastrointest Endosc 2000; 52: 328-32.

4. Tada M, Murata M, Muratami F. Development of the strip-off biopsy (in Japanese with English abstract). Gastroenterol Endosc 1984; 26 : 833-9.

5. Kojima T, Parra-Blanco A, Takahashi H, Fujita R. Outcome of endoscopic mucosal resection for early gastric cancer: review of the Japanese literature. Gastrointest Endosc 1998; 48: 550-5.

6. Inoue H, Takeshita K, Hori H, Muraoka Y, Yoneshima H, Endo M. Endoscopic mucosal resection with a cap-fitted panendoscope for esophagus, stomach and colon mucosal lesions. Gastrointest Endosc 1993; 39: 58-62.
7. Ono H, Kondo H, Gotoda T, et al. Endoscopic mucosal resection for treatment of early gastric cancer. Gut 2001; 48: 225-9.

8. Soehendra N, Seewald S, Groth S, Omar S, Seitz U, Zhong Y, et al. Use of modified multiband ligator facilitates circumferential EMR in Barrett's esophagus Gastrointest Endosc 2006; 63: 847-52.

9. May A, Gossner L, Behrens A, Kohnen R, Vieth M, Stolte M, et al. A prospective randomized trial of two different endoscopic resection techniques for early stage cancer of the esophagus. Gastrointest Endosc 2003; 58: 167-75.

10. Mino-Kenudson M, Hull MJ, Brown I, Muzikansky A; Srivastava A, Glickman J, et al. EMR for Barrett's esophagus-related superficial neoplasms offers better diagnostic reproducibility than mucosal biopsy. Gastrointest Endosc 2007; 66: 660-6.

11. Buskens CJ, Westerterp M, Lagarde SM, Bergman JJ, ten Kate FJ, van Lanschot JJ. Prediction of appropriateness of local endoscopic treatment for high-grade dysplasia and early adenocarcinoma by EUS and histopathologic features. Gastrointest Endosc 2004; 60(5): 703-10.

12. Soetikno RM, Gotoda T, Nakanishi Y, Soehendra N. Endoscopic mucosal resection. Gastrointest Endosc 2003; 57: 567-79.

13. Vázquez-Iglesias JL, Alonso-Aguirre PA, Centeno A, López E, Rodríguez T, Blanco S. Riesgo de perforación en la mucosectomía esofágica con banda: Estudio experimental con dos modelos de ligadores. Rev Esp Enferm Dig 2007; 99: 84-7.

14. Katada C, Muto M, Manabe T, Boku N, Ohtsu A, Yoshida S. Esophageal stenosis after endoscopic mucosal resection of superficial esophageal lesions. Gastrointest Endosc 2003; 57(2): 165-9.

15. Parkin DM, Bray FI, Devesa SS. Cancer burden in the year 2000 . The global picture. Eur J Cancer 2001; 37(Supl. 8): S4-66.

16. Torii A, Sakai M, Inoue K, Yamabe H, Ueda S, Okuma M. A clinicopathological analysis of early gastric cancer: retrospective study with special reference to lymph node metastasis. Cancer Detect Prev 1994; 18(6): 437-41.

17. Everett SM, Axon AT. Early gastric cancer in Europe. Gut 1997; 41(2): 142-50.

18. Noda M, Kodama T, Atsumi M, Nakajima M, Sawai N, Kashima K, et al. Possibilities and limitations of endoscopic resection for early gastric cancer. Endoscopy 1997; 29(5): 361-5. 